\title{
The Animal-foods-environment interface of Klebsiella pneumoniae in Germany: an observational study on pathogenicity, resistance development and the current situation
}

\author{
Gamal Wareth ${ }^{1,2^{*}}$ (D) and Heinrich Neubauer ${ }^{1}$
}

\begin{abstract}
Klebsiella (K.) pneumoniae as a multi-drug resistant (MDR) pathogen is an emerging challenge for clinicians worldwide. Virulence factors are capsular antigens, adherence factors, the O-lipopolysaccharide, and siderophores promoting infectivity. Mechanisms of antimicrobial resistance are inactivation of compounds via enzymes, change of membrane permeability, and alteration of the target site of the antimicrobial compound. In addition to environmental resistance, K. pneumoniae can survive increasing concentrations of disinfectants, if exposed. This review describes the temporal and spatial distribution of K. pneumoniae in the past decades in Germany, with emphases on the development of resistance in the non-human columns of the One-Health concept. In general, K. pneumoniae is a neglected pathogen in veterinary and environmental health, and the risk of human infection concerning animal contact and food consumption is barely investigated. Few reports exist $(n=26)$ on antibiotic resistance of isolates from non-human origin. Multi-drug resistance and extended-spectrum $\beta$-lactamase (MDR-ESBL) strains also resistant to carbapenems and antibiotics of the B-lactam group harbor blaCTX-M, blaOXA, blaTEM, blaSHV, blaCMY, and PMQR have been found in animals, foods, and the environment. Colistin resistant strains carrying the $\mathrm{mcr}-1$ gene were detected in wastewater. The blaCTX-M-15 and blaOXA-48 genes are the most frequently identified AMR genes in isolates of humans and were also the most predominant ESBL-genes in samples collected from animal hosts. Several aspects of the molecular epidemiology and resistance development of $K$. pneumoniae in farm animal populations, wildlife, and foods need intensive research. Environmental health has to be integrated into national research plans, as a lack of data is apparent. Increasing awareness of the fact that non-human sources can act as a reservoir for this pathogen has to be raised.
\end{abstract}

Keywords: Klebsiella pneumoniae, review, occurrence, resistance development, pathogenicity, Germany

\section{Table of Contents}

1 Introduction

2 Background

*Correspondence: gamal.wareth@fli.de

${ }^{1}$ Friedrich-Loeffler-Institut, Institute of Bacterial Infections and Zoonoses, Naumburger Street 96a, 07743 Jena, Germany

Full list of author information is available at the end of the article
2.1 Factors relevant to the pathogenicity of Klebsiella pneumoniae

2.2 Resistance mechanisms in Klebsiella pneumoniae

3 Spatio-temporal distribution of $K$. pneumoniae in non-human reservoirs in Germany

3.1 Search strategy

3.1.1 Data acquisition and extraction

3.1.2 Data setting and analysis

c) The Author(s) 2020. This article is licensed under a Creative Commons Attribution 4.0 International License, which permits use, sharing, adaptation, distribution and reproduction in any medium or format, as long as you give appropriate credit to the original author(s) and the source, provide a link to the Creative Commons licence, and indicate if changes were made. The images or other third party material in this article are included in the article's Creative Commons licence, unless indicated otherwise in a credit line to the material. If material is not included in the article's Creative Commons licence and your intended use is not permitted by statutory regulation or exceeds the permitted use, you will need to obtain permission directly from the copyright holder. To view a copy of this licence, visit http://creativeco mmons.org/licenses/by/4.0/. The Creative Commons Public Domain Dedication waiver (http://creativecommons.org/publicdomain/ zero/1.0/) applies to the data made available in this article, unless otherwise stated in a credit line to the data. 
3.2 The situation in animal hosts

3.2.1 Klebsiella pneumoniae in farm and companion animals

3.2.2 Klebsiella pneumoniae in wildlife

3.3 The situation in foods

3.4 The situation in the environment

4 Discussion

5 Conclusion

References

\section{Introduction}

Members of the genus Klebsiella $(K$.) belong to the family Enterobacteriaceae. They are Gram-negative, non-motile, usually capsulated, facultatively anaerobic bacteria. They are found in different environmental sources such as water and soil [1]. Up-to-date, the genus encompasses eight species: K. pneumoniae, which includes three subspecies (subspecies pneumoniae, ozaenae, and rhinoscleromatis); K. oxytoca; K. planticola; K. ornithinolytica; K. granulomatis; K. mobilis, K. terrigena and K. variicola [2]. Klebsiella pneumoniae is responsible for most human infections and one of the most critical multi-drug resistance (MDR) microorganisms worldwide [3]. The pathogen was found in the digestive, urinary, and respiratory tract of humans and can cause septic infection [4]. It is also found in a variety of environmental sources such as soil, water, and vegetation. It is often present in a wide range of domestic and wild mammals as well as in insects and has been also recovered from foods [5]. In animals, it is an essential cause of pneumonia, epidemic metritis, and cervicitis in mares and septicemia in foals [6]. It has been frequently associated with pneumonia and mastitis in bovines [7] leading to high losses in milk production, decreased milk quality, and even high mortalities among affected cows [8]. Consequently, infection can result in noticeable economic losses in the dairy industry, even in well-managed dairy farms [9]. However, its prevalence is increasing in dairy herds as well as in the food chain, research focusing on $K$. pneumoniae still very rare in veterinary medicine, and the risk of human infection after animal contact and food consumption is not well studied at all. Little information is available on the impact of $K$. pneumoniae infections on livestock welfare and productivity, epidemiology, resistance profiles, and resistance development in isolates of non-human sources.

Rapid dissemination and thus the rate of isolation of MDR K. pneumoniae strains are increasing in humans in Europe. In Germany, this trend is seen since the late twentieth century. Several strains with diverse antimicrobial resistance (AMR) gene patterns were isolated from several German states [10]. According to data from the Antibiotic Resistance Surveillance System (ARS), the European Antimicrobial Resistance Surveillance Network (EARS-Net) system and Surveillance of Antibiotic Use and Resistance in Intensive Care Units (SARI), the prevalence of MDR K. pneumoniae is dramatically increasing over the past few years in the human population [11]. Also the seriousness of the clinical outcomes is increasing over time [12].

\section{Background}

\subsection{Factors relevant to the pathogenicity of Klebsiella pneumoniae}

Klebsiella pneumoniae utilizes a variety of virulence factors. Although several genes involved in K. pneumoniae pathogenesis have been identified, their role in virulence [13] and resistance [14] is not entirely understood, as research only just begun. Four main components have long been associated with the pathogenesis of K. pneumoniae: $\mathrm{K}$-capsular antigens, adherence factors, O-lipopolysaccharide (LPS), and siderophores [2]. Capsular Polysaccharide (K-antigen) was the first virulence factor described for Klebsiella. This antigen forms a thick hydrophilic capsule and is responsible for the glistening and mucoid appearance of $K$. pneumoniae colonies on agar plates. Up-to-date, at least $78 \mathrm{~K}$-antigen serotypes have been characterized called K1, K2, etc. [15]. The K-antigens play a significant role in protection against opsonophagocytosis and against killing by serum [2]. Previous studies in a mouse model showed that K1 and K2 serotypes were more virulent than others. However, not all serotypes have been tested in animal models yet $[16,17]$. Adhesions are often hemagglutinins located on fimbriae that protrude on the surface of the bacterial cells and are responsible for hemagglutination (HA). Klebsiella pneumoniae produces two types of fimbrial adhesions, type 1 and type 3 fimbriae. The thick-channeled (type-1) fimbriae, which are responsible for D-mannose-sensitive hemagglutination (MS-HA) are expressed by $80 \%$ of all K. pneumoniae strains. Clinical strains produce these fimbriae more often than in environmental isolates [18]. Thin, non-channeled (type-3) fimbriae, cause "mannose-resistant, Klebsiellalike hemagglutination" (MR/K-HA) and it expressed in more than $85 \%$ of $K$. pneumoniae strains and is encoded by the $m r k$ gene cluster [18]. Additional adhesions were found to play a role in pathogenesis such as the non-fimbrial $29 \mathrm{kDa}$ adhesin "CF29K." [19], and the novel fimbrial adhesin "KPF-28" [20]. These adhesions are responsible for adherence of $K$. pneumoniae to intestinal cells and human carcinoma cells, respectively. Lipopolysaccharide (LPS) is composed of lipid A, a core polysaccharide, and a side chain called the "O-antigen". Nine types of $\mathrm{O}$-antigen are distinguished in K. pneumoniae and play a significant 
role in protection against complement-mediated killing $[21,22]$. O1 is the most common antigen and is linked to extensive tissue necrosis. Siderophores or iron-scavenging systems are small, high-affinity iron-chelating compounds secreted by microorganisms and taken up again after they have "collected" Fe ions. Klebsiella pneumoniae is able to induce four to six iron-repressible outer-membrane proteins during infection. Enterochelin and aerobactin are secreted to solubilize and import the required iron ions during infection [23]. Recently, a third siderophore encoded by the Yersinia high-pathogenicity island called "yersiniabactin" was shown to be also present in K. pneumoniae, but its role in pathogenesis is still unknown [24]. The production of yersiniabactin was demonstrated in $17.7 \%$ of K. pneumoniae strains isolated from blood cultures and urine in hospitalized patients in Munich [25]. Additionally, there are other potential virulence factors like hemolysins produced in rabbit blood agar [26], heatlabile, and heat-stable enterotoxin [27], a protein-tyrosine kinase and a phosphotyrosine-protein phosphatase [28] which may be involved in the synthesis of capsular polysaccharide. Still, different aspects of K. pneumoniae pathogenicity e.g. infectious dose and incubation period are unknown.

\subsection{Resistance mechanisms in Klebsiella pneumoniae}

Klebsiella pneumoniae poses a public health concern because it is one of the 'ESKAPE' pathogens, the most common MDR pathogens worldwide encompassing six bacterial pathogens (Enterococcus faecium, Staphylococcus aureus, Klebsiella pneumoniae, Acinetobacter baumannii, Pseudomonas aeruginosa, and Enterobacter species). It evades antimicrobial action with a variety of mechanisms including enzymatic degradation or inactivation of antimicrobial compounds, changing of membrane permeability, and modifying the target site of antimicrobial compounds by mutation of bacterial proteins. German K. pneumoniae strains have developed and acquired a massive variety of extended-spectrum $\beta$-lactamase enzymes (ESBL), which inhibit $\beta$-lactam antibiotics such as penicillins, cephalosporins, and carbapenems [29]. Genes responsible for enzyme inactivation are often located on mobile genetic elements (MGE) and provide a risk of transfer to other bacteria [30]. ESBL strains resistant to penicillins and cephalosporins were recovered from horses, dogs and cats admitted to veterinary clinics, and from European mouflons [31-33]. Changes in membrane permeability to antimicrobial compounds occur due to increased efflux or reduced influx of these compounds. MDR $K$. pneumoniae produce e.g. AmpC $\beta$-lactamase accompanied by loss of OmpK35 and OmpK36 proteins [34]. First reported German carbapenem-resistant $K$. pneumoniae strains had developed resistance through the loss of the porin channel protein OmpK36 and increased expression of a tripartite AcrAB-TolC efflux pump [35]. The occurrence of carbapenem-resistant $K$. pneumoniae is scarcely reported in animal hosts, probably because carbapenems use is forbidden in veterinary medicine. A carbapenemaseproducing strain harboring blaOXA-48 was isolated from dogs in 2013 [36]. This genotype was reported again in studies with samples collected between 2012 and 2016 from dogs, cats, guinea pigs, rats, rabbits, and mice [37]. Mechanisms identified for the alteration of bacterial proteins to modify the target site of drugs were activation of ribosome-protective proteins, methylation of the ribosomal binding site, and amino acid exchanges in target genes due to mutations as in the case of resistance to fluoroquinolone. Klebsiella pneumoniae isolates resistant to fluoroquinolones were reported in Germany since 2003 [38]. In 2018, two plasmid-mediated quinoloneresistant $(\mathrm{PMQR})$ strains that carried native oq $x \mathrm{AB}$ genes were reported from a dog. These strains were collected in 2014 during a study on the characterization of quinolone resistance mechanisms in Enterobacteriaceae from companion animals in Europe. They had mutations in the quinolone resistance-determining regions (QRDR) of the GyrA and ParC genes [39]. It can be supposed that German isolates of $K$. pneumoniae can develop all three types of resistance mechanisms.

\section{Spatio-temporal distribution of K. pneumoniae in non-human reservoirs in Germany}

The number of reservoirs for resistant bacteria is increasing in hospitals, the community, and livestock as well as in the environment [40]. Therefore, transmission pathways between humans, animal hosts, and the environment are currently a subject of active discussion. Monitoring and understanding the current situation of resistance development and epidemiology of this pathogen in animals, foods, and the environment is necessary to combat this public health threat.

\subsection{Search strategy}

\subsubsection{Data acquisition and extraction}

In the present work, articles focusing on K. pneumoniae in Germany until September 2020 obtained through searches in PubMed, Scopus, and Web of science. Following search terms were used: Klebsiella pneumoniae in Germany+antimicrobial-resistant + animals + food + environment. Articles discussing isolation and resistance profiles of $K$. pneumoniae are included. Studies dealing with human cases and other Klebsiella species were excluded. Title and abstract analysis of each publication and the full text of selected articles were analyzed. 


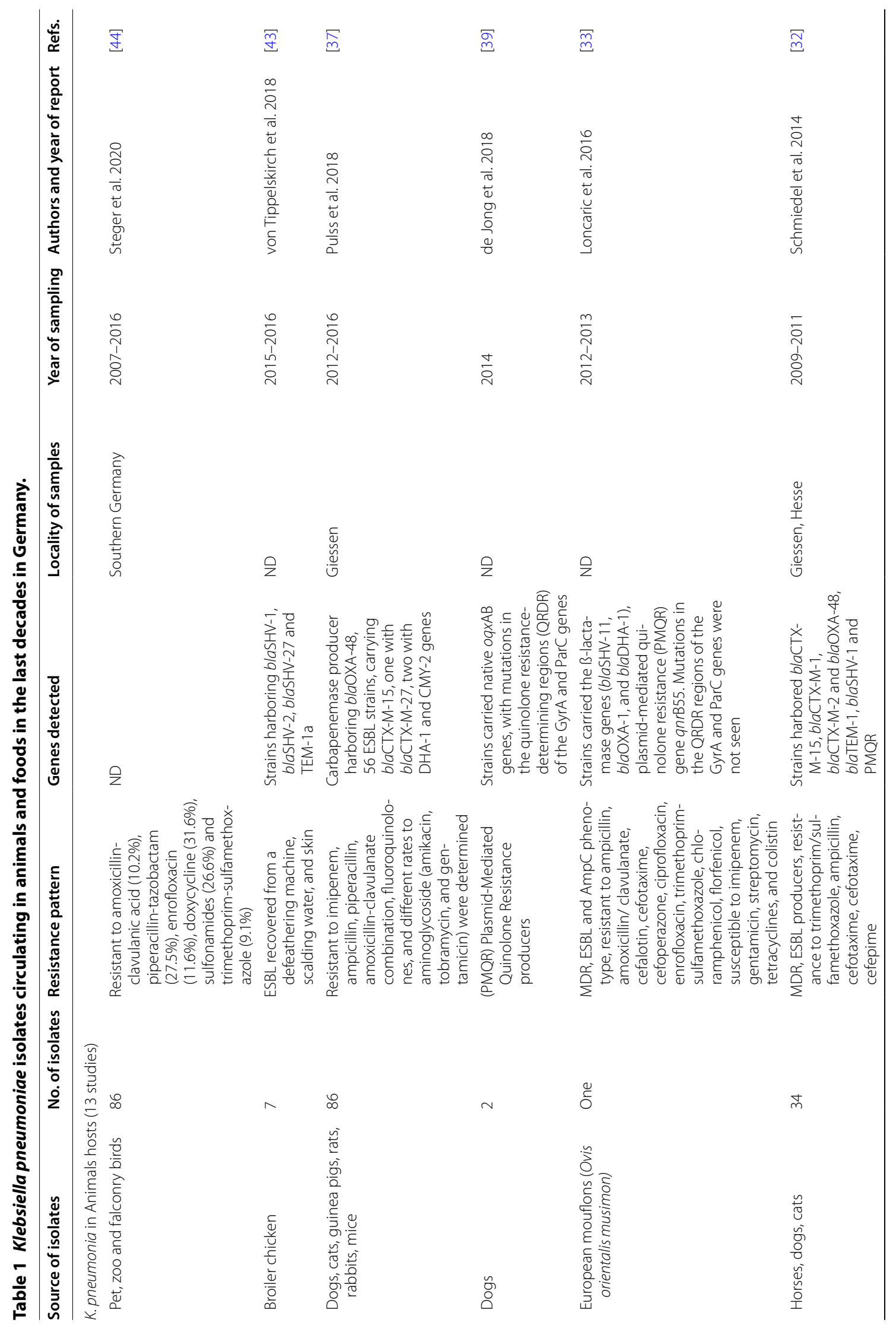




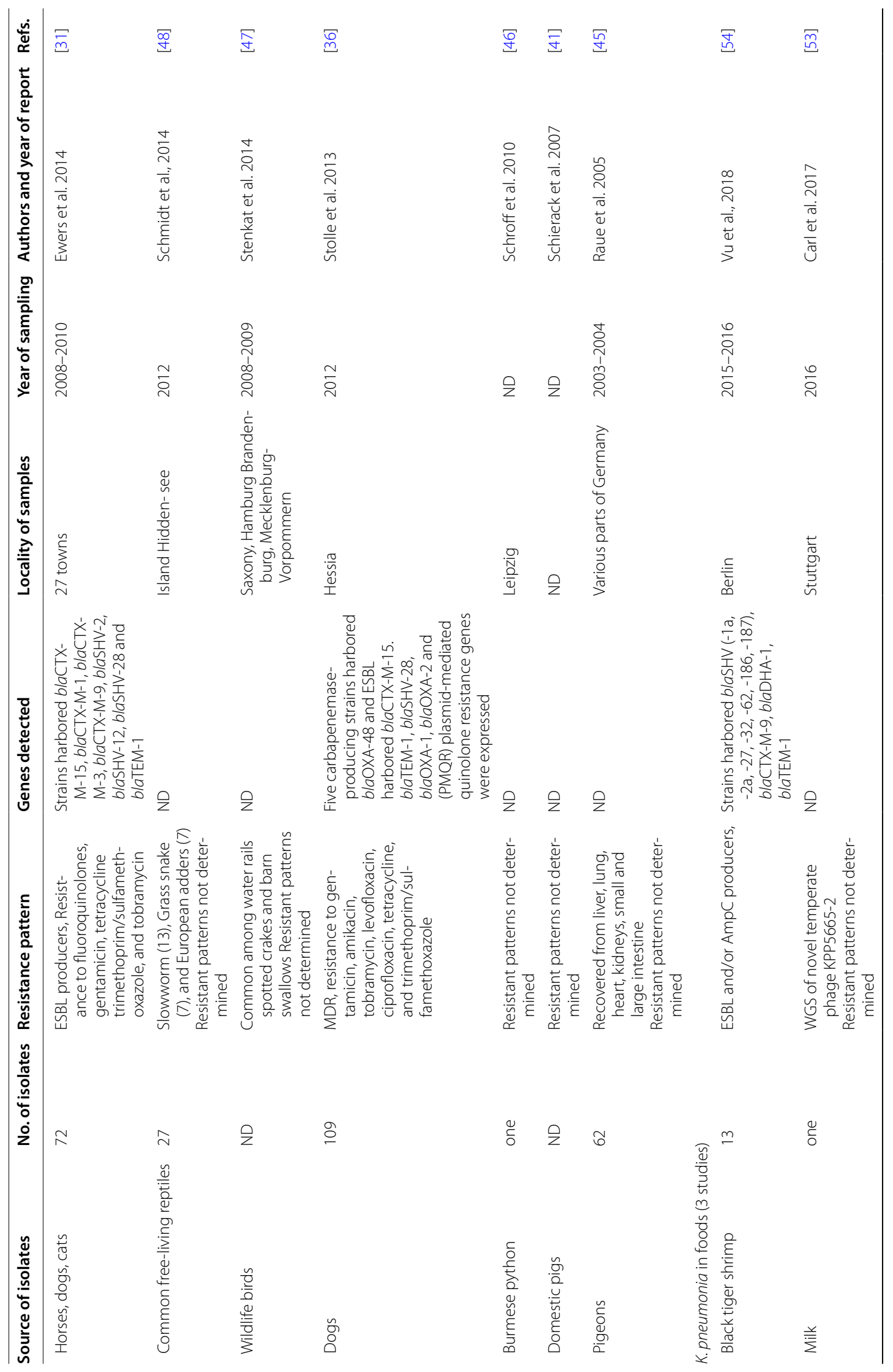




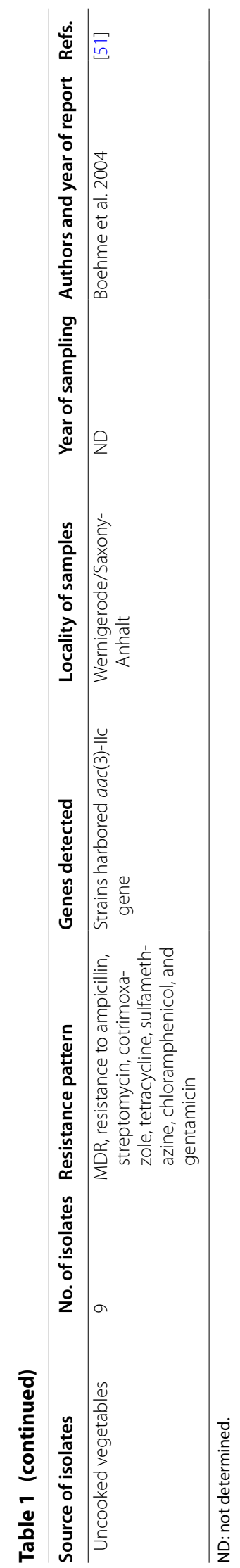




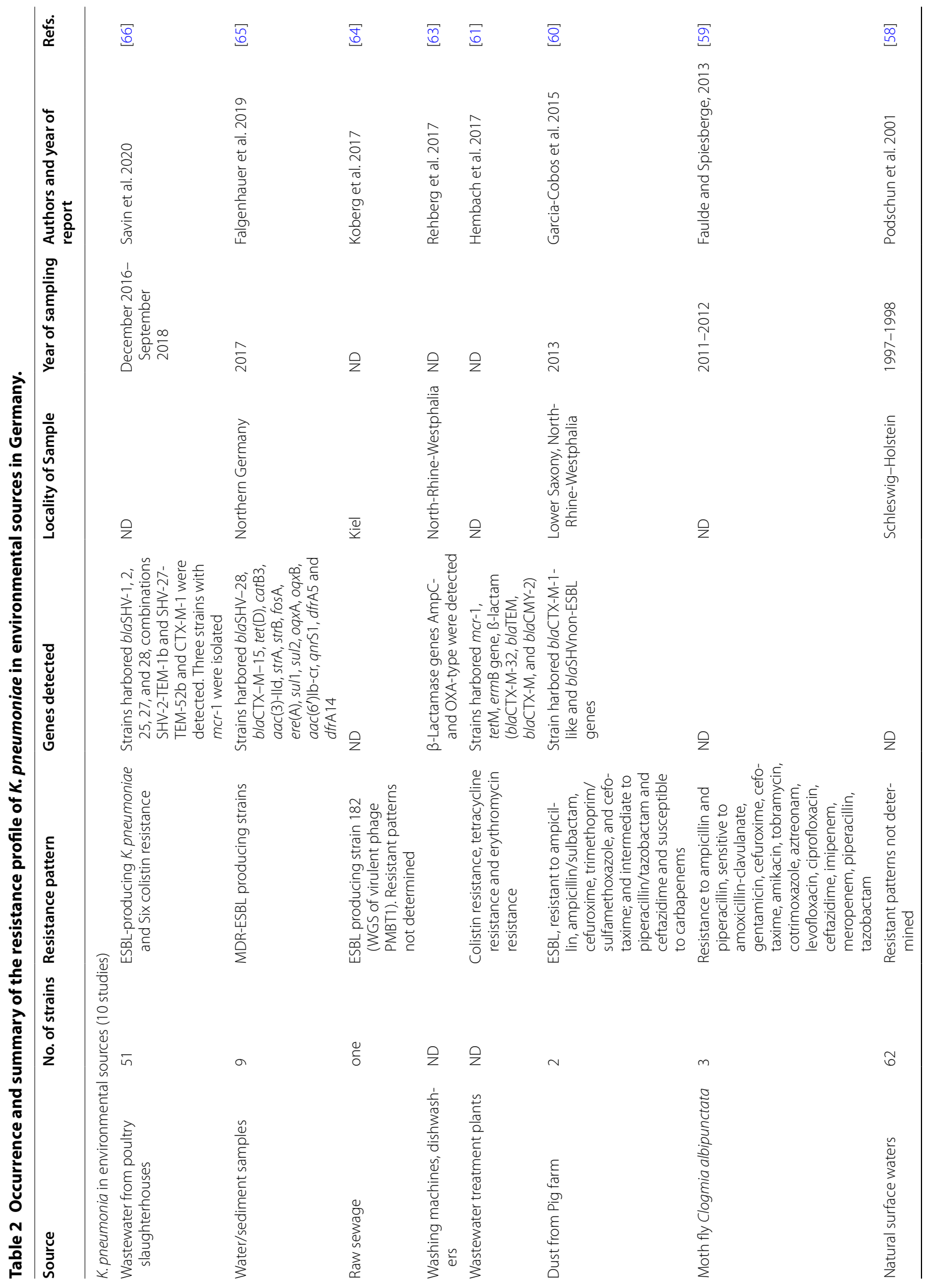




\subsubsection{Data setting and analysis}

From 618 articles found, 125 were investigated. Ninetynine articles are related to human studies (data not shown), and only 26 articles about prevalence and resistance development of $K$. pneumoniae in non-humans sources were identified [animal hosts $(n=13)$, foods $(\mathrm{n}=3)$, and environmental sources $(\mathrm{n}=10)]$. The articles were published in a period from 1985 until September 2020. Seventeen studies were discussing the resistance patterns of strains, while the other nine articles were dealing only with isolation. The information was categorized chronically from the latest to the oldest article according to the year of publication based on host, source, and origin of isolates, the number of strains in each study, resistance profile and resistance genes present, location and time of sampling. The full details of the literature search are shown in Tables 1 and 2.

\subsection{The situation in animal hosts \\ 3.2.1 Klebsiella pneumoniae in farm and companion animals}

Klebsiella pneumoniae recovered from clinical samples collected from companion and farm animals i.e. dogs, cats, horses, rabbits and rats, and chicken and pigs, respectively. Investigations on the composition of the intestinal Enterobacteriaceae populations of healthy pigs revealed that K. pneumoniae was detected in $84 \%$ of the subgroup of mucosa-associated bacteria, but the resistance pattern of these strains was not determined [41]. MDR carbapenemase and ESBL-producing strains were isolated from samples of soft tissues, urinary tract infections, the respiratory tract, the genital tract, wounds, and feces of dogs, cats, and horses [31, 32, 36]. A total of $109 \mathrm{~K}$. pneumoniae strains was isolated from dogs between June and October 2012 in Hessia. Five isolates from the same veterinary clinic were carbapenem-resistant and harbored blaOXA-48 genes. All strains were clonally related, co-expressed ESBL of the blaCTX-M-15 type, and harbored plasmid-mediated quinolone resistance genes [36]. In between October 2008 to March 2010, 72 ESBL producing $K$. pneumoniae subsp. pneumoniae strains were recovered from companion animals including horses admitted to 30 veterinary clinics in 27 different towns in Germany [31]. The clonal group carrying blaCTX-M-15 was the most predominant type, while the blaCTX-M-1 group was less frequent. It is worth to mention that blaCTX-M-15 is the most prevalent ESBL in K. pneumoniae and has recently emerged in humans [42]. It is considered a zoonotic agent of high relevance to humans and animals [32, 42]. Between 2009 and 2011, 34 MDR-ESBL producing strains were recovered from dogs, cats, and horses admitted to veterinary clinics in Giessen [32]. Interestingly, isolates from companion animals, 
horses, and humans shared the same characteristics: presence of ESBL, carbapenemase OXA-48 and plasmidencoded quinolone resistance (PMQR) genes. It is speculated that this coincidence of common features might prove the active transmission and dissemination of MDR genes between humans and animal populations in Germany [32]. However, this assumption needs further proof. Investigation of urine samples collected from dogs in 2014 revealed the presence of two PMQR producer strains, which carried native oqxAB genes [39]. Carbapenemase producer strains harboring blaOXA-48 and ESBL producers harboring blaCTX-M-15 and blaCTX-M-27 were detected in samples collected from dogs, cats, rabbits, guinea pigs, and mice between June 2012 and December 2016 [37]. The apparent relatedness of strains from different clinics investigated in that study points to the spread of this clone via animal carriers between various clinics, eventually contaminating the clinical environments [37]. Recently, ESBL strains harboring blaSHV-1, -2, -27, and TEM-1a were cultured from the skin of chicken broilers and a defeathering machine on the same farm [43]. Investigation of bacteria in samples collected between 2007 and 2016 from pet birds, zoo birds and falconry birds in Southern Germany revealed $86 \mathrm{~K}$. pneumoniae isolates. The strains were resistance to doxycycline (31.6\%), piperacillin-tazobactam (27.5\%), sulfonamides (26.6\%), enrofloxacin (11.6\%), amoxicillin-clavulanic acid (10.2\%) and trimethoprim-sulfamethoxazole (9.1\%) [44]. The full details of our literature search are shown in Table 1.

\subsubsection{Klebsiella pneumoniae in wildlife}

Klebsiella pneumoniae strains were recovered from internal organs (liver, kidney, heart, lung, small and large intestine) of pigeons captured in various parts of Germany between 2003 and 2004 [45], from snakes (Burmese python) suffering from pneumonia at Leipzig zoo [46]. Strains were also cultured from cloacal and pharyngeal swabs collected between 2008 and 2009 from free-living birds e.g. water rails (Rallus aquaticus), spotted crakes (Porzana porzana) and barn swallows (Hirundo rustica) in Saxony, Hamburg, Brandenburg, and MecklenburgVorpommern [47]. In another study, 27 isolates were recovered from apparently healthy free-living reptiles on the island of Hiddensee in northeastern Germany. Seven strains were cultured from European adders (Vipera berus), seven isolates from grass snakes (Natrix natrix), and thirteen isolates from slow worms (Anguis fragilis) [48]. None of the previous studies aimed to characterize the resistance patterns for the strains or look for the existence of resistant genes. In contrast, the resistance profiles of MDR ST/11 strains isolated from nasal and perineal swabs of European mouflons (Ovis orientalis musimon) were investigated. The strains were collected between 2012 and 2013 and were ESBL and had an AmpC phenotype. They also carried several ß-lactamases and non- $ß$-lactamases plasmid-mediated quinolone resistance (PMQR) genes [33] (Table 1). Klebsiella pneumoniae was reported recently as one of the etiological bacterial agents causing death among the exotic captive amphibian pet and zoo animals in Germany [49].

\subsection{The situation in foods}

Since manure is brought from animal farming to field and green land, resistant bacteria may spread to plants and the environment. Foodborne bacteria are extensively studied, but research on K. pneumoniae is scarce. Klebsiella pneumoniae has been recovered from various food samples, but especially from fresh raw chicken meat [5] and fresh vegetables worldwide [50]. Only three studies discussing the existence of $K$. pneumoniae in the food chains in Germany were found. Screening of twenty uncooked vegetables of different kinds i.e. tomatoes, salads, carrots, cauliflower, mushrooms, etc. as well as sprouts samples from Wernigerode/SaxonyAnhalt revealed the presence of nine MDR K. pneumoniae strains in rocket salad and mung bean sprouts [51]. The strains were resistant to ampicillin, streptomycin, tetracycline, chloramphenicol, sulfamethazine, cotrimoxazole, and kanamycin. Interestingly, one strain isolated from the pre-enrichment culture of sprouts was resistant to gentamicin and harbored the aac (3)-IIa gene [51]. Consumption of seed sprouts is a growing in market as an alternative product overall Europa. Outbreaks with pathogenic bacteria caused by contaminated sprouts demonstrated the risk of disseminate to humans via this route [52]. In 2016, a K. pneumoniae strain was isolated from a German mastitis milk sample by the CVUA-Stuttgart, Baden-Wuerttemberg [53]. The presence of resistant strains in milk is a threat to vulnerable animals and humans. Between December 2015 and August 2016, 160 retail raw seafood samples i.e. white leg shrimp, black tiger shrimp, blue mussels, venus clams, razor shells, and cockles were collected from a market in Berlin. Most of animals were originally harvested abroad. Thirteen ESBL and AmpC-producing $K$. pneumoniae were isolated from black tiger shrimps. Two samples from products were originally from Vietnam, and one from Bangladesh, while the rest could not be traced back to their country/ ies of origin [54]. The strains were harboring blaSHV-1a $(-2 \mathrm{a},-27,-32,62,-186$, and -187$)$, blaCTX-M-9, blaDHA-1, and blaTEM-1 [54]. The samples used in that study were collected at retail markets. Therefore, the bacteria and AMR genes of those samples could have different origin, including wholesale handling, retail handling 
in supermarkets, the washing process, distribution, and seafood shops. That study highlights the potential hazards associated with seafood containing ESBL and AmpC producing K. pneumoniae in Germany. The presence of multi-resistance bacteria in foods is of concern to public health. Recently, evaluation of antibiotic resistance dissemination by wastewater treatment plant (WWTP) effluents with different catchment areas in Germany revealed that the daily discharge of $K$. pneumoniae in food-producing impacted WWTP effluents is higher compared to communal and hospital-impacted WWTP effluents [55].

\subsection{The situation in the environment}

Klebsiella pneumoniae can be found in a variety of environments such as soil, water, and vegetation. In Germany, K. pneumoniae strains resistant to gentamicin and trimethoprim were isolated continuously from raw wastewater [56]. From May 1982 to January 1983 and March 1986 to May 1986, K. pneumoniae were collected from water specimens from the Rhine and its affluxes in the Rhine-Neckar-Region. At that time, the use of this water as unprocessed drinking water, for bathing, and for agriculture purposes was not acceptable [57]. From November 1997 to June 1998, 208 natural surface waters samples were collected from 196 different sampling sites at streams, lakes, and the Baltic Sea in Schleswig-Holstein. Among 123 Klebsiella strains isolated, K. pneumoniae was the most common species $(n=62)$ [58]. From June 2011 to May 2012, three strains resistant to ampicillin and piperacillin were recovered from adult moth flies (Clogmia albipunctata) captured around hospitals [59]. In 2013, two multi-resistant ESBL-producing strains were found in dust samples collected from pig farms in the federal states of Lower Saxony and North Rhine-Westphalia (NRW) [60]. Both strains were resistant to ampicillin, ampicillin/sulbactam, cefuroxime, cefotaxime, and trimethoprim/sulfamethoxazole and harboring the blaCTX-M-1-like and blaSHV non-ESBL genes. Colistin resistant strains carrying the $m c r-1$ gene were found in higher abundances in wastewater treatment plants even at effluent sampling sites [61]. In addition to $m c r-1$, the strains were harboring tetracycline tet $\mathrm{M}$ and erythromycin erm $\mathrm{B}$ resistance genes, and ß-lactamase (blaCTX-M-32, blaTEM, blaCTX-M, and CMY-2) genes. It is worth to mention that colistin-resistant strains carrying the $m c r-1$ gene were isolated in the same year from human samples collected from a leukemia patient in April 2015 at Frankfurt am Main [62]. Strains harboring $\beta$-lactamase AmpC- and OXA-type genes were detected in domestic washing machines and dishwashers in North Rhine-Westphalia [63]. MDR ESBL- K. pneumoniae strains were recovered from a sewage plant located in Kiel, northern Germany [64]. Hence, opportunistic pathogens and clinically relevant antibiotic resistance genes in wastewaters bear the risk of dissemination to the aquatic environment and from there to humans. Recently, hypervirulent $K$. pneumoniae isolates of four different sequence types (ST268, ST307, ST2155 and ST 3681) were isolated from water and sediment samples collected from water treatment plants in the neighborhood of a slaughterhouse in northern Germany. The strains were MDR and harbored blaSHV-28, blaCTX-M-15, tet(D), cat $\mathrm{B} 3$, $\operatorname{acc}(3)$-IId, strA, strB, fos $\mathrm{A}, \operatorname{ere}(\mathrm{A}), \operatorname{sul} 1, \operatorname{sul} 2, o q x \mathrm{~A}$, $o q x \mathrm{~B}, a a c\left(6^{\prime}\right) \mathrm{Ib}-\mathrm{cr}, q u r \mathrm{~S} 1, d f r \mathrm{~A} 5$ and $d f r \mathrm{~A} 14$ [65]. These findings indicate the possible spread of MDR K. pneumoniae into the animal population. Fifty-one ESBL-producing $K$. pneumoniae strains were isolated from wastewater effluents of two poultry slaughterhouses between December 2016 and September 2018. The strains harbored the blaSHV-1, 2, 25, 27, and 28, a combinations of blaSHV-2-TEM-1b and blaSHV27-TEM-52b, and CTX-M-1. Among them, six colistin resistance strains were identified, and $m c r-1$ was detected only in three [66]. The full details of our literature search are shown in Table 2.

\section{Discussion}

Over the last decades, an alarming worldwide increase of MDR in K. pneumoniae strains isolated from humans has been noted, while the prevalence in wildlife species, farm and companion animals and the environment is not significantly investigated. The presence of MDR $K$. pneumoniae in animals and foods poses three significant problems. Firstly, the treatment of infection in animals will be challenging as the bacteria are resistant to various antibiotics approved for veterinary medicine. Secondly, the development of MDR strains in animal hosts and along the food chain may result in the development of reservoir with contamination or infection of humans finally. Thirdly, genes responsible for resistance are mainly plasmid-mediated and often located on mobile genetic elements (MGE) [30], which favors spread to obligate pathogens. Lateral gene transfer of a gene homologous of ramR of Salmonella enterica were identified in five isolates of $K$. pneumoniae resulting in reduced susceptibility to tigecycline [67]. Klebsiella pneumoniae is a common cause of bovine pneumonia, metritis, and mastitis. It can be assumed that milk can be easily contaminated during milking. The prevalence is increasing in dairy herds as well as in the food chain [68]. However, it is neglected in companion and other food-producing animals in Germany, and the risk of human infection 
concerning animal contact and food consumption is not well investigated. The present study highlights that MDR K. pneumoniae harboring several AMR genes are present in samples from animals, foods and the environment. For One-Health, these results are alarming and pin point the risk for the dissemination of resistance genes between animals, the environment, and healthcare professionals. New strategies are needed to control and prevent the evolution of MDR K. pneumoniae in veterinary hospitals i.e. reducing exposure of animals to antibiotics in the veterinary medicine. It is also crucial to screen and implement hygiene strategies to minimize spread. Collaboration between veterinary and public health professionals to combat antimicrobial resistance is supreme.

Klebsiella pneumoniae has been recovered from domestic animals, wildlife, the environment, and foods. Hence, only a few studies $(\mathrm{n}=26)$ investigating $K$. pneumoniae in those non-human reservoirs were done from 1985 to September 2020. The blaCTX-M-15 and blaOXA-48 were the most predominant ESBL-genes in samples collected from companion animals and horses, and these are also the genes most often associated with antibiotic resistance in isolates of humans origin in Germany [32, 42]. The clonal group carrying blaCTX-M-15 can be considered a zoonotic agent of high relevance. Strains recovered from animal and human samples were found to share the presence of PMQR and OXA-48 genes, highlighting possible dissemination and transmission of the MDR genes between human and animal populations [32]. The hypervirulent $K$. pneumoniae ST268 was frequently associated with human disease and has been isolated from different surface waters in Northern Germany [65]. Colistin resistant strains carrying the $m c r-1$ gene was reported in 2015 in samples obtained from humans [62] and also detected at a higher rate in wastewater treatment plants [61]. The use of colistin in the treatment of MDR bacterial infection is continually increasing, resulting in emerging of colistin resistance $K$. pneumoniae in several countries worldwide and Europe [69].

As stated in the antibiotic resistance and consumption report (GERMAP 2015 report) which concern with the consumption of antimicrobials and the spread of antimicrobial resistance in human and veterinary medicine in Germany, K. pneumoniae is one of the main pathogens causing environmental mastitis in cattle. Since 2005/2006, the National Resistance Monitoring of Animal Pathogenic Bacteria (GERM-Vet) try to monitor Klebsiella spp. isolates from cows, and the 2013 study year included 39 strains. Comparing the results of the study years revealed that the resistance of Klebsiella were in an acceptable "not too high" range. However, the development of ESBLs requires special monitoring to be able to anticipate the trend in resistance development. The GERM-Vet report concluded that isolates from the "udder" compartment in dairy cattle showed significantly more favorable susceptibility levels than human strains in respect to antimicrobials used in veterinary medicine [70]. According to the antimicrobial surveillance report launched by the European Centre for Disease Prevention and Control (ecdc) in 2015, combined resistance to third-generation cephalosporins, fluoroquinolones, and aminoglycosides was prevalent in more than a third of the $K$. pneumoniae isolates reported to EARS-Net. However, this finding did not remain significant in Germany because only data from laboratories reporting consistently for 2012 to 2015 has been considered. The situation in neighboring EU countries is not much different. Klebsiella pneumoniae was extensively investigated in humans, but very few studies have been carried out on animals and foods. Between 2013 and 2014, PMQR-containing K. pneumoniae strains were isolated from dogs in Belgium, Spain, Poland, the Czech Republic [39], and K. pneumoniae was representing $2.3 \%$ of 7,806 bacterial isolates recovered from diseased equines in France between 2016 and 2019 [71]. Strains harbouring blaCTX-M-1, blaOXA-1, qnrB, aac(6), aac(6)-Ib, catB3, blaSHV, $q r n \mathrm{~B}, q n r \mathrm{~S}, a p h \mathrm{~A}, \operatorname{sul} 1$ and $d f r A 12$ were isolated from dogs in Austria [72]. Comparative analysis of the epidemiology of K. pneumoniae in the EU countries and building up a network of researchers from these countries to investigate AMR in K. pneumoniae will greatly improve AMR surveillance.

\section{Conclusion}

The current knowledge on the general distribution and antibiotic resistance in K. pneumoniae from domestic animals, wildlife, the environment, and foods in Germany is scarce. Food and environmental sources are playing a significant role in the transmission of antibiotic-resistant bacteria or their corresponding resistance determinants between animals and humans and from country to country. They are considered a concern for food and drinking water safety. The presence of MDR K. pneumoniae in foods, water and environment is alarming, and the potential health risks posed by such a way should not be underestimated. Increased awareness of public health and veterinary health is required. Further investigation of MDR pathogens in animals and the food chain is needed to clarify the transmission of AMR genes.

\footnotetext{
Abbreviations

AMR: antimicrobial resistance; ESBL: extended-spectrum $\beta$-lactamase; GERMVet: The National Resistance Monitoring of Animal Pathogenic Bacteria; HA: hemagglutination; K: Klebsiella; LPS: lipopolysaccharide; MDR: multi-drug resistant; MGE: mobile genetic elements:; MR/K-HA: "mannose-resistant, Klebsiella-like hemagglutination"; MS-HA: D-mannose-sensitive hemagglutination:; NRW: North Rhine-Westphalia; QRDR: quinolone resistance-determining regions; WWTP: Wastewater treatment plant.
} 


\section{Acknowledgements}

Not applicable for the statement

\section{Authors' contributions}

Both authors read and approved the final manuscript.

\section{Funding}

Open Access funding enabled and organized by Projekt DEAL.. Open Access funding enabled and organized by Projekt DEAL. The work has been funded internally by FLI.

\section{Availability of data and materials \\ All data are available in the tables.}

\section{Ethics approval and consent to participate}

Not required.

\section{Consent for publication}

Obtained.

\section{Competing interest}

The authors declare no competing interest.

\section{Author details}

${ }^{1}$ Friedrich-Loeffler-Institut, Institute of Bacterial Infections and Zoonoses, Naumburger Street 96a, 07743 Jena, Germany. ${ }^{2}$ Faculty of Veterinary Medicine, Benha University, Moshtohor, Toukh 13736, Egypt.

Received: 30 September 2020 Accepted: 3 December 2020 Published online: 08 February 2021

\section{References}

1. Melo-Nascimento A, Treumann C, Neves C, Andrade E, Andrade AC, Edwards R, Dinsdale E, Bruce T (2018) Functional characterization of ligninolytic Klebsiella spp. strains associated with soil and freshwater. Arch Microbiol 200:1267-1278

2. Brisse S, Grimont F, Grimont PAD (2006) The Genus Klebsiella. In: Dworkin M, Falkow S, Rosenberg E, Schleifer K-H, Stackebrandt E (eds) The prokaryotes: volume 6: proteobacteria: gamma subclass. Springer, New York, pp 159-196

3. Santajit S, Indrawattana N (2016) Mechanisms of antimicrobial resistance in ESKAPE pathogens. Biomed Res Int 2016:2475067

4. Bradley ME, Scoular SK (2019) Metastatic Klebsiella pneumoniae Invasive liver abscess syndrome in Denver, Colorado. J Pharm Pract. https://doi. org/10.1177/0897190019882867

5. Guo Y, Zhou H, Qin L, Pang Z, Qin T, Ren H, Pan Z, Zhou J (2016) Frequency, antimicrobial resistance and genetic diversity of Klebsiella pneumoniae in food samples. PLoS One 11:e0153561

6. Kikuchi N, Blakeslee JR, Hiramune T (1995) Plasmid profiles of Klebsiella pneumoniae isolated from horses. J Vet Med Sci 57:113-115

7. Saishu N, Ozaki H, Murase T (2014) CTX-M-type extended-spectrum betalactamase-producing Klebsiella pneumoniae isolated from cases of bovine mastitis in Japan. J Vet Med Sci 76:1153-1156

8. Hertl JA, Schukken YH, Welcome FL, Tauer LW, Grohn YT (2014) Pathogenspecific effects on milk yield in repeated clinical mastitis episodes in Holstein dairy cows. J Dairy Sci 97:1465-1480

9. Paulin-Curlee GG, Sreevatsan S, Singer RS, Isaacson R, Reneau J, Bey R, Foster D (2008) Molecular subtyping of mastitis-associated Klebsiella pneumoniae isolates shows high levels of diversity within and between dairy herds. J Dairy Sci 91:554-563

10. RKI, Epidemiologisches Bulletin (2013). Robert Koch Institut 2013, no 19, pp 167-171. http://www.rki.de/DE/Content/Infekt/EpidBull/Archiv/2013/ Ausgaben/19_13.pdf?_blob=publicationFile
11. Remschmidt C, Schneider S, Meyer E, Schroeren-Boersch B, Gastmeier P, Schwab F (2017) Surveillance of antibiotic use and resistance in intensive care units (SARI). Dtsch Arztebl Int 114:858-865

12. Eckmanns T, Richter D, Feig M (2014) MRSA and ESBL in outpatient: development from 2008 up to 2012 and socio demographic differences. Berl Munch Tierarztl Wochenschr 127:399-402

13. Lai YC, Lin GT, Yang SL, Chang HY, Peng HL (2003) Identification and characterization of KvgAS, a two-component system in Klebsiella pneumoniae CG43. FEMS Microbiol Lett 218:121-126

14. Liu L, Ye M, Li X, Li J, Deng Z, Yao YF, Ou HY (2017) Identification and characterization of an antibacterial type $\mathrm{VI}$ secretion system in the carbapenem-resistant strain Klebsiella pneumoniae HS11286. Front Cell Infect Microbiol 7:442

15. Hsu CR, Lin TL, Pan YJ, Hsieh PF, Wang JT (2013) Isolation of a bacteriophage specific for a new capsular type of Klebsiella pneumoniae and characterization of its polysaccharide depolymerase. PLoS One 8:e70092

16. Simoons-Smit AM, Verwey-van Vught AM, Kanis IY, MacLaren DM (1984) Virulence of Klebsiella strains in experimentally induced skin lesions in the mouse. J Med Microbiol 17:67-77

17. Mizuta K, Ohta M, Mori M, Hasegawa T, Nakashima I, Kato N (1983) Virulence for mice of Klebsiella strains belonging to the $\mathrm{O} 1$ group: relationship to their capsular (K) types. Infect Immun 40:56-61

18. Podschun R, Sahly H (1991) Hemagglutinins of Klebsiella pneumoniae and K. oxytoca isolated from different sources. Zentralbl Hyg Umweltmed 191:46-52

19. Darfeuille-Michaud A, Jallat C, Aubel D, Sirot D, Rich C, Sirot J, Joly B (1992) R-plasmid-encoded adhesive factor in Klebsiella pneumoniae strains responsible for human nosocomial infections. Infect Immun 60:44-55

20. Di Martino P, Livrelli V, Sirot D, Joly B, Darfeuille-Michaud A (1996) A new fimbrial antigen harbored by CAZ-5/SHV-4-producing Klebsiella pneumoniae strains involved in nosocomial infections. Infect Immun 64:2266-2273

21. Hansen DS, Mestre F, Alberti S, Hernández-Allés S, Alvarez D, DoménechSánchez A, Gil J, Merino S, Tomás JM, Benedí VJ (1999) Klebsiella pneumoniae lipopolysaccharide $O$ typing: revision of prototype strains and O-group distribution among clinical isolates from different sources and countries. J Clin Microbiol 37:56-62

22. Straus DC, Atkisson DL, Garner CW (1985) Importance of a lipopolysaccharide-containing extracellular toxic complex in infections produced by Klebsiella pneumoniae. Infect Immun 50:787-795

23. Williams P, Chart H, Griffiths E, Stevenson P (1987) Expression of high affinity iron uptake systems by clinical isolates of Klebsiella. FEMS Microbiol Lett 44:407-412

24. Koczura R, Kaznowski A (2003) Occurrence of the Yersinia high-pathogenicity island and iron uptake systems in clinical isolates of Klebsiella pneumoniae. Microb Pathog 35:197-202

25. Schubert S, Cuenca S, Fischer D, Heesemann J (2000) High-pathogenicity island of Yersinia pestis in enterobacteriaceae isolated from blood cultures and urine samples: prevalence and functional expression. J Infect Dis 182:1268-1271

26. Albesa I, Eraso AJ, Frigerio Cl, Lubetkin AM (1980) Outbreak of hospital infection, due to members of the Klebsielleae tribe, in an intensive care unit for infants. Rev Argent Microbiol 12:39-43

27. Klipstein FA, Engert RF, Houghten RA (1983) Immunological properties of purified Klebsiella pneumoniae heat-stable enterotoxin. Infect Immun 42:838-841

28. Preneta R, Jarraud S, Vincent C, Doublet P, Duclos B, Etienne J, Cozzone AJ (2002) Isolation and characterization of a protein-tyrosine kinase and a phosphotyrosine-protein phosphatase from Klebsiella pneumoniae, Comparative biochemistry and physiology. Part B Biochem Mol Biol 131:103-112

29. Lohr B, Pfeifer Y, Heudorf U, Rangger C, Norris DE, Hunfeld KP (2017) High prevalence of multidrug-resistant bacteria in Libyan war casualties admitted to a tertiary care hospital, Germany. Microb Drug Resist. https://doi. org/10.1089/mdr.2017.0141 
30. Schwarz S, Cloeckaert A, Roberts M (2006) Mechanisms and spread of bacterial resistance to antimicrobial agents. In: Aarestrup F (ed) Antimicrobial Resistance in Bacteria of Animal Origin. ASM Press, Washington, pp 73-98

31. Ewers C, Stamm I, Pfeifer Y, Wieler LH, Kopp PA, Schonning K, PrengerBerninghoff E, Scheufen S, Stolle I, Gunther S, Bethe A (2014) Clonal spread of highly successful ST15-CTX-M-15 Klebsiella pneumoniae in companion animals and horses. J Antimicrob Chemother 69:2676-2680

32. Schmiedel J, Falgenhauer L, Domann E, Bauerfeind R, Prenger-Berninghoff E, Imirzalioglu C, Chakraborty T (2014) Multiresistant extendedspectrum beta-lactamase-producing Enterobacteriaceae from humans, companion animals and horses in central Hesse, Germany. BMC Microbiol $14: 187$

33. Loncaric I, Beiglbock C, Fessler AT, Posautz A, Rosengarten R, Walzer C, Ehricht R, Monecke S, Schwarz S, Spergser J, Kubber-Heiss A (2016) Characterization of ESBL- and AmpC-Producing and fluoroquinolone-resistant Enterobacteriaceae isolated from mouflons (Ovis orientalis musimon) in Austria and Germany. PLoS One 11:e0155786

34. Thomson JM, Bonomo RA (2005) The threat of antibiotic resistance in Gram-negative pathogenic bacteria: beta-lactams in peril! Curr Opin Microbiol 8:518-524

35. Grobner S, Linke D, Schutz W, Fladerer C, Madlung J, Autenrieth IB, Witte W, Pfeifer Y (2009) Emergence of carbapenem-non-susceptible extended-spectrum beta-lactamase-producing Klebsiella pneumoniae isolates at the university hospital of Tubingen Germany. J Med Microbiol 58:912-922

36. Stolle I, Prenger-Berninghoff E, Stamm I, Scheufen S, Hassdenteufel E, Guenther S, Bethe A, Pfeifer Y, Ewers C (2013) Emergence of OXA-48 carbapenemase-producing Escherichia coli and Klebsiella pneumoniae in dogs. J Antimicrob Chemother 68:2802-2808

37. Pulss S, Stolle I, Stamm I, Leidner U, Heydel C, Semmler T, PrengerBerninghoff E, Ewers C (2018) Multispecies and clonal dissemination of OXA-48 carbapenemase in Enterobacteriaceae from companion animals in Germany, 2009-2016. Front Microbiol 9:1265

38. Wagenlehner FM, Heisig P, Irtenkauf C, Notka F, Decker J, Lehn N, Linde $H$ (2003) Clinically significant borderline resistance of sequential clinical isolates of Klebsiella pneumoniae. Int J Antimicrob Agents 22:367-373

39. de Jong A, Muggeo A, El Garch F, Moyaert H, de Champs C, Guillard T (2018) Characterization of quinolone resistance mechanisms in Enterobacteriaceae isolated from companion animals in Europe (ComPath II study). Vet Microbiol 216:159-167

40. Guerra B, Fischer J, Helmuth R (2014) An emerging public health problem: acquired carbapenemase-producing microorganisms are present in food-producing animals, their environment, companion animals and wild birds. Vet Microbiol 171:290-297

41. Schierack P, Walk N, Reiter K, Weyrauch KD, Wieler LH (2007) Composition of intestinal Enterobacteriaceae populations of healthy domestic pigs. Microbiology (Reading, England) 153:3830-3837

42. Zhou X, Garcia-Cobos S, Ruijs G, Kampinga GA, Arends JP, Borst DM, Moller LV, Holman ND, Schuurs TA, van BruijnesteijnCoppenraet LE, Weel JF, van Zeijl JH, Kock R, Rossen JWA, Friedrich (2017) Epidemiology of extended-spectrum beta-lactamase-producing E coli and vancomycin-resistant Enterococci in the Northern Dutch-German cross-border region. Front Microbiol. 8:1914

43. von Tippelskirch P, Golz G, Projahn M, Daehre K, Friese A, Roesler U, Alter T, Orquera S (2018) Prevalence and quantitative analysis of ESBL and AmpC beta-lactamase producing Enterobacteriaceae in broiler chicken during slaughter in Germany. Int J Food Microbiol 281:82-89

44. Steger $L$, Rinder M, Korbel R (2020) [Phenotypical antibiotic resistances of bacteriological isolates originating from pet, zoo and falconry birds], Tierarztliche Praxis. Ausgabe K Kleintiere/Heimtiere 48:260-269

45. Raue R, Schmidt V, Freick M, Reinhardt B, Johne R, Kamphausen L, Kaleta EF, Muller H, Krautwald-Junghanns ME (2005) A disease complex associated with pigeon circovirus infection, young pigeon disease syndrome. Avian Pathol 34:418-425
46. Schroff S, Schmidt V, Kiefer I, Krautwald-Junghanns ME, Pees M (2010) Ultrasonographic diagnosis of an endocarditis valvularis in a Burmese python (Python molurus bivittatus) with pneumonia. J Zoo Wildlife Med 41:721-724

47. Stenkat J, Krautwald-Junghanns ME, Schmitz OA, Eilers A, Schmidt V (2014) Aerobic cloacal and pharyngeal bacterial flora in six species of free-living birds. J Appl Microbiol 117:1564-1571

48. Schmidt V, Mock R, Burgkhardt E, Junghanns A, Ortlieb F, Szabo I, Marschang R, Blindow I, Krautwald-Junghanns M-E (2014) Cloacal aerobic bacterial flora and absence of viruses in free-living slow worms (Anguis fragilis), grass snakes (Natrix natrix) and european adders (Vipera berus) from Germany. EcoHealth 11:571-580

49. Hallinger MJ, Taubert A, Hermosilla C (2020) Endoparasites infecting exotic captive amphibian pet and zoo animals (Anura, Caudata) in Germany. Parasitol Res. https://doi.org/10.1007/s00436-020-06876-0

50. Touati A, Mairi A, Baloul Y, Lalaoui R, Bakour S, Thighilt L, Gharout A, Rolain JM (2017) First detection of Klebsiella pneumoniae producing OXA-48 in fresh vegetables from Bejaia city Algeria. J Glob Antimicrob Resist 9:17-18

51. Boehme S, Werner G, Klare I, Reissbrodt R, Witte W (2004) Occurrence of antibiotic-resistant enterobacteria in agricultural foodstuffs. Mol Nutr Food Res 48:522-531

52. Taormina PJ, Beuchat $L R$, Slutsker $L$ (1999) Infections associated with eating seed sprouts: an international concern. Emerg Infect Dis 5:626-634

53. Carl G, Jackel C, Grutzke J, Hertwig S, Grobbel M, Malorny B, Rau J, Kasbohrer A, Hammerl JA (2017) Complete genome sequence of the temperate Klebsiella pneumoniae phage KPP5665-2. Genome Announc. https://doi.org/10.1128/genomeA.01118-17

54. Vu TTT, Alter T, Roesler U, Roschanski N, Huehn S (2018) Investigation of extended-spectrum and AmpC beta-lactamase-producing Enterobacteriaceae from retail seafood in Berlin Germany. J Food Protect. 81:1079-1086

55. Alexander J, Hembach N, Schwartz T (2020) Evaluation of antibiotic resistance dissemination by wastewater treatment plant effluents with different catchment areas in Germany. Sci Rep 10:8952

56. Stelzer W, Ziegert E, Schneider E (1985) Occurrence of antibiotic-resistant klebsiellas in waste water. Zentralblatt fur Mikrobiologie 140:283-291

57. Mersch-Sundermann V, Wundt W (1987) Bacteriologic quality of water from the Rhine and its tributaries in the Rhine-Neckar region I. Bacterial count and Enterobacteriaceae of the current status of pollution. Zentralbl Bakteriol Mikrobiol Hyg B 184:459-469

58. Podschun R, Pietsch S, Holler C, Ullmann U (2001) Incidence of Klebsiella species in surface waters and their expression of virulence factors. Appl Environ Microbiol 67:3325-3327

59. Faulde M, Spiesberger M (2013) Role of the moth fly Clogmia albipunctata (Diptera: Psychodinae) as a mechanical vector of bacterial pathogens in German hospitals. J Hosp Infect 83:51-60

60. Garcia-Cobos S, Kock R, Mellmann A, Frenzel J, Friedrich AW, Rossen JW (2015) Molecular typing of Enterobacteriaceae from pig holdings in North-Western Germany reveals extended-spectrum and AmpC betalactamases producing but no carbapenem resistant ones. PLoS ONE 10:e0134533

61. Hembach N, Schmid F, Alexander J, Hiller C, Rogall ET, Schwartz T (2017) Occurrence of the $\mathrm{mcr}-1$ colistin resistance gene and other clinically relevant antibiotic resistance genes in microbial populations at different municipal wastewater treatment plants in Germany. Front Microbiol 8:1282

62. Tietgen M, Semmler T, Riedel-Christ S, Kempf VAJ, Molinaro A, Ewers C, Gottig S (2017) Impact of the colistin resistance gene $m c r-1$ on bacterial fitness. Int J Antimicrob Agents. https://doi.org/10.1016/j.ijantimica g.2017.11.011 
63. Rehberg L, Frontzek A, Melhus A, Bockmuhl DP (2017) Prevalence of beta-lactamase genes in domestic washing machines and dishwashers and the impact of laundering processes on antibiotic-resistant bacteria. J Appl Microbiol 123:1396-1406

64. Koberg S, Brinks E, Fiedler G, Husing C, Cho GS, Hoeppner MP, Heller KJ, Neve H, Franz CM (2017) Genome sequence of Klebsiella pneumoniae bacteriophage PMBT1 isolated from raw sewage. Genome Announc. https://doi.org/10.1128/genomeA.00914-16

65. Falgenhauer L, Schwengers O, Schmiedel J, Baars C, Lambrecht O, Heß S, Berendonk TU, Falgenhauer J, Chakraborty T, Imirzalioglu C (2019) Multidrug-resistant and clinically relevant Gram-negative bacteria are present in German surface waters. Front Microbiol 10:2779

66. Savin M, Bierbaum G, Hammerl JA, Heinemann C, Parcina M, Sib E, Voigt A, Kreyenschmidt J (2020) ESKAPE bacteria and extended-spectrum- $\beta$ lactamase-producing Escherichia coli isolated from wastewater and process water from German poultry slaughterhouses. Appl Environ Microbiol 86(8):e02748-e2819. https://doi.org/10.1128/AEM.02748-19

67. Hentschke M, Wolters M, Sobottka I, Rohde H, Aepfelbacher M (2010) ramR mutations in clinical isolates of Klebsiella pneumoniae with reduced susceptibility to tigecycline. Antimicrob Agents Chemother 54:2720-2723

68. Yang Y, Higgins CH, Rehman I, Galvao KN, Brito IL, Bicalho ML, Song J, Wang H, Bicalho RC (2019) Genomic diversity, virulence, and antimicrobial resistance of Klebsiella pneumoniae strains from cows and humans. Appl Environ Microbiol. https://doi.org/10.1128/AEM.02654-18
69. Ah YM, Kim AJ, Lee JY (2014) Colistin resistance in Klebsiella pneumoniae. Int J Antimicrob Agents 44:8-15

70. Kaspar H (2015) GERMAP 2015-antimicrobial resistance and consumption. 123. ISBN 978-3-9818383-0-5

71. Léon A, Castagnet S, Maillard K, Paillot R, Giard JC (2020) Evolution of in vitro antimicrobial susceptibility of equine clinical isolates in France between 2016 and 2019. Animals (Basel) 10(5):812. https://doi. org/10.3390/ani10050812

72. Loncaric I, Misic D, Szostak MP, Künzel F, Schäfer-Somi S, Spergser J (2020) Broad-spectrum cephalosporin-resistant and/or fluoroquinoloneresistant enterobacterales associated with canine and feline urogenital infections. Antibiotics 9(7):387. https://doi.org/10.3390/antibiotics9070 387

\section{Publisher's Note}

Springer Nature remains neutral with regard to jurisdictional claims in published maps and institutional affiliations.
Ready to submit your research? Choose BMC and benefit from:

- fast, convenient online submission

- thorough peer review by experienced researchers in your field

- rapid publication on acceptance

- support for research data, including large and complex data types

- gold Open Access which fosters wider collaboration and increased citations

- maximum visibility for your research: over $100 \mathrm{M}$ website views per year

At BMC, research is always in progress.

Learn more biomedcentral.com/submissions 